This item was submitted to Loughborough's Research Repository by the author.

Items in Figshare are protected by copyright, with all rights reserved, unless otherwise indicated.

\title{
The relative success of alternative approaches to strategic information systems planning: an empirical analysis
}

\section{PLEASE CITE THE PUBLISHED VERSION}

http://dx.doi.org/10.1016/S0963-8687(99)00024-4

PUBLISHER

(C) Elsevier

\section{VERSION}

AM (Accepted Manuscript)

\section{LICENCE}

CC BY-NC-ND 4.0

\section{REPOSITORY RECORD}

Doherty, Neil, C.G. Marples, and A. Suhaimi. 2019. "The Relative Success of Alternative Approaches to Strategic Information Systems Planning: An Empirical Analysis”. figshare. https://hdl.handle.net/2134/8185. 
This item was submitted to Loughborough's Institutional Repository (https://dspace.lboro.ac.uk/) by the author and is made available under the following Creative Commons Licence conditions.

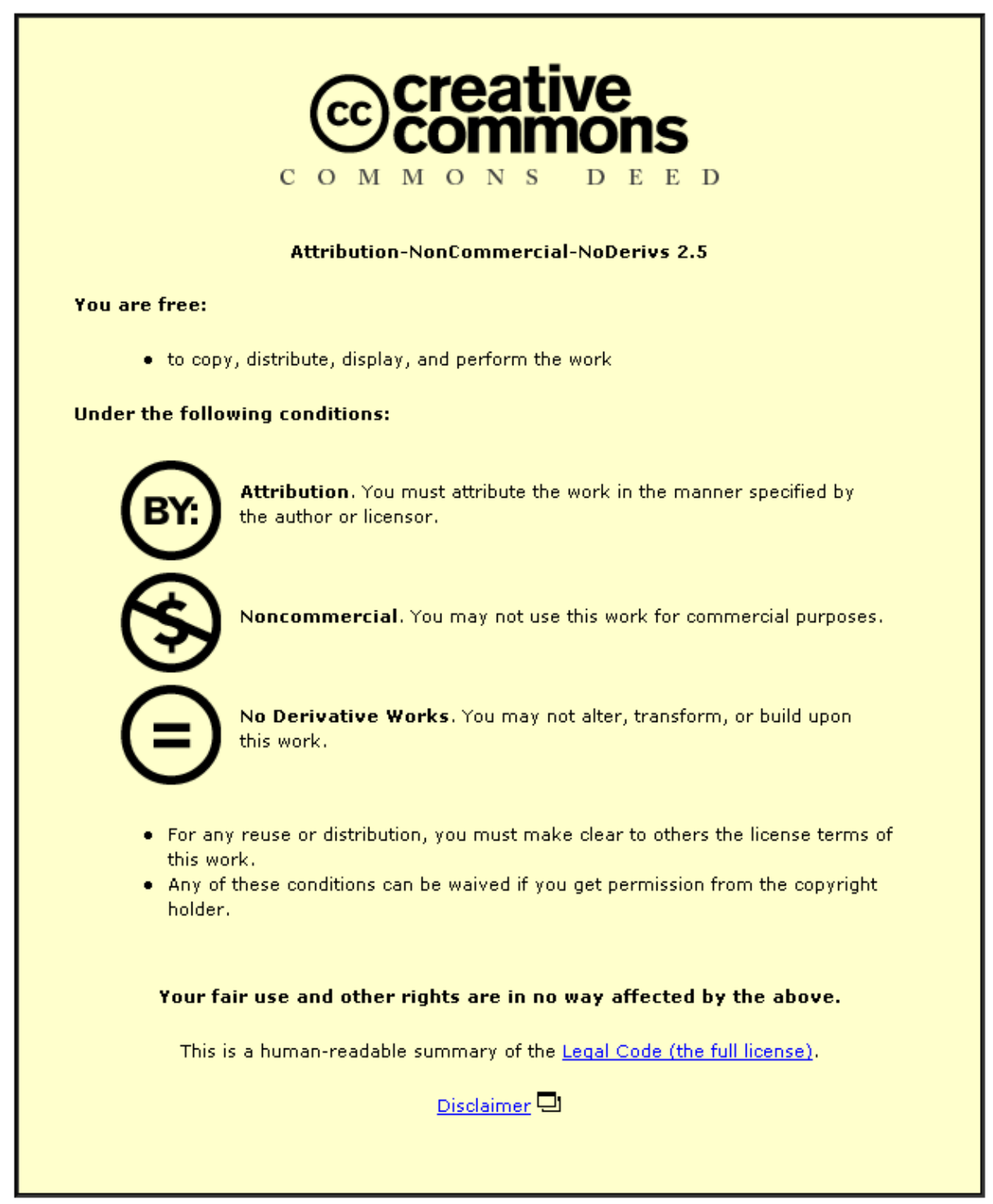

For the full text of this licence, please go to: http://creativecommons.org/licenses/by-nc-nd/2.5/ 


\title{
The Relative Success of Alternative Approaches to Strategic Information Systems Planning: An Empirical Analysis
}

\author{
N. F. DOHERTY, C. G. MARPLES, \\ (The Business School, Loughborough University) \\ A. SUHAIMI \\ (The Islamic University, Kuala Lumpa, Malaysia)
}

Address for correspondence:

Dr Neil F. Doherty,

The Business School,

Loughborough University,

Loughborough,

LE11 3TU,

United Kingdom.

Telephone: 01509223128

Email: n.f.doherty@lboro.ac.uk 
Abstract: Strategic information systems planning (SISP) is an exercise or ongoing activity that enables organisations to develop priorities for IS development. It has been suggested that the 'SISP approach', a combination of method, process and implementation, is the most complete way of describing SISP activity. Based upon questionnaire responses from 267 IT Directors, four distinct approaches to SISP have been derived using cluster analysis. A comparison of these four approaches with Earl's [1993] five approaches indicates that three bear strong similarities to the 'organisational', 'business-led', and 'administrative' approaches, whilst the fourth cluster is related to both Earl's 'method-driven' and 'technological' approaches. An analysis of the relationship between SISP approach and SISP success, demonstrates that the 'organisational approach' is significantly more successful than the other three approaches.

\section{Introduction}

Strategic information systems planning (SISP) is an exercise or ongoing activity that enables organisations to develop priorities for IS development. Applications are chosen for their alignment with business objectives or their capacity to create significant impact on the organisation's competitive positioning. Improving strategic information systems planning practices has rapidly become one of the most critical issues facing IS executives today [Lederer and Sethi, 1988; Nierderman et al, 1991; Clark, 1992; Galliers 1993; Galliers et al, 1994; Segars et al, 1998a]. As the perceived importance of information systems planning has steadily increased over the past ten years, so interest in the methods and approaches by which it is undertaken has also risen. It has been noted [Lederer and Sethi, 1988; Earl, 1993; Segars et al, 1998a] that there has been a strong tendency within the IS literature to focus upon the role and effectiveness of specific planning methods, rather than to consider the broader set of practices which influence the application of planning within a specific organisation. Unfortunately, such research with its strong method orientation often fails to take into account other important aspects of the process of strategic information systems planning, such as the level of participation, the ownership of the project or the focus of the planning exercise. Consequently, Earl [1993] has suggested that the 'SISP approach', a combination of method, process and implementation, is the most complete way of describing SISP activity.

To build upon the work of Earl [1993] and Segars [1994], a research project was initiated to gain further insights into the importance and relevance of the SISP approach. More specifically the research presented in this paper reports on the application of multi-variate statistical techniques to a large set of questionnaire responses, relating to SISP planning practices, with a view to identifying a number of distinct approaches in the application of SISP. The following section of this paper discusses the concept of strategic information systems planning, as it is portrayed in the literature, before establishing the research objectives for this project. The development, validation, targeting and distribution of a postal 
questionnaire survey are described in section three. The research results are presented in a series of tables that are discussed in the fourth section, and their importance is assessed in the final section.

\section{Approaches to Strategic Information Systems Planning}

This section establishes a definition of the term, strategic information systems planning (SISP), and then reviews the methods and approaches by which SISP is applied. In so doing, the objectives of this research are established.

\subsection{From ISP to SISP}

The planning of a development schedule for information systems - ISP - based generally on user demand and financial justification, has been practised since businesses first turned to information technology. Indeed, by the late 1970s, information systems managers were already using ISP, to improve communication with IS users; encourage senior management support; forecast resource requirements; allocate resources, and to find opportunities for improving the performance of the IS department [McLean \& Soden, 1977].

The concept of SISP - strategic planning of information systems - evolved during the 1980s [Lederer and Sethi, 1988]. The most significant differences between SISP, and the planning practices that pre-dated it, were in terms of its explicit emphasis on strategic alignment and competitive impact. For example, Lederer and Sethi [1988] adopt a broad, two-sided view of SISP. On the one hand, SISP is viewed as 'the process of identifying a portfolio of computerbased applications that will assist an organization in executing its business plans and consequently realizing its business goals', whilst on the other hand SISP entails 'searching for applications with a high impact and with the ability to create an advantage over competitors'. Similarly, Earl [1993] suggests that two key defining aspects of SISP are 'aligning investment in IS with business goals' and 'exploiting IT for competitive advantage'. Based on these perspectives, the following composite definition of SISP has been derived for the purposes of this study:

'The process of identifying a portfolio of computer-based applications to be implemented, which is both highly aligned with corporate strategy and has the ability to create an advantage over competitors.'

Within this definition, the 'process of identifying' should provide satisfaction that effort has been well spent in analysing the operation of the organisation to achieve general agreement on development priorities. The importance of strategic information systems planning has been well documented within the IS literature. For example, it has been suggested that the 
application of SISP: facilitates the integration of the IS function within the organisation [King, 1978]; supports the identification of opportunities to use information systems for strategic purposes [Ward, 1987]; ensures that adequate resources are allocated to critical applications [Lederer and Mendelow, 1989]; and ensures that the IS function supports organisational goals and activities at every level [Lederer and Sethi, 1991]. A broad body of literature has therefore evolved that strongly signals the importance of SISP. Unfortunately, there are a variety of problems within the process of SISP that can inhibit its success (Lederer and Sethi, 1992), and consequently, the search for robust methods, tools and approaches to support its application continues to be of great importance.

\subsection{The Practice of SISP: from Methodology to Approach}

The choice of a SISP methodology is a critical issue on the IS planning agenda, providing as it does the organisational setting in which the IS decisions are made [Lederer \& Sethi, 1988]. Many organisations, therefore, adopt a specific methodology, such as: Business Systems Planning (BSP), Method/1, Information Engineering (IE) or PROplanner, as a framework for applying SISP. According to Earl [1993], however, methods typically only focus on the technique, procedure, or methodology employed. Consequently, methods are not sufficient for directing the application of SISP as they often overlook process concerns, such as the need for line management participation, or the importance of implementation issues. Consequently, Earl [1993] suggested that a SISP approach comprising a mix of procedures, techniques, user-IS interactions, special analyses, and random discoveries, is a more balanced way of viewing the application of SISP. More specifically, the elements of an approach can be defined as the nature and place of method, the attention to and style of process, and the focus on and probability of implementation. Based on these observations, Earl [1993] was able to identify five distinct SISP approaches; the 'business-led', 'organisational', 'administrative', technological' and 'method-driven' approaches. Furthermore, Earl [1993] was also able to relate each of the above approaches to a number of measures of effectiveness and concluded that whilst the 'organisational' approach was the most successful, the 'administrative' approach enjoyed the least success.

Other authors have explored the concept of the SISP approach. For example, Sabherwal and King [1995] studied SISP approaches by identifying 8 key attributes. The first four: analysis, planning, delay and politics, represent planning activities, while the final four: external influence, internal influence, top management influence and IS influence, represent influencing forces. Their study of 85 cases against the 8 attributes led to 5 distinct clusters, labelled planned, provincial, incremental, fluid and political, each representing a particular decision making process, or approach. Similarly, Byrd et al. [1995] characterised SISP by attributes representing institutionalised planning dimensions, actions and behaviours. Notably, Segars et al [1998a] suggest that there is a single approach, rational adaptation, that is the most effective way to practise IS planning. Rational adaptation is characterised against six planning dimensions: comprehensiveness, formalisation, focus, flow, participation 
and consistency. In each of these studies, a number of planning dimensions are used to characterise cases, in order to provide the taxonomy of approaches. However, there is still much research to be undertaken in this area to fully understand the role and significance of the SISP approach. In particular, it is necessary to study the relative levels of success of alternative SISP approaches in order to provide better advice to IT professionals with regard to the successful application of SISP.

\subsection{The Successful Application of SISP}

A comprehensive review of the recent IS planning literature reveals that the following factors are related to the success of the IS planning process:

1. the need to align the corporate objectives with the IS strategy [Henderson \& Venkatramman, 1993]

2. the underlying motivation for the initialisation of the planning process [Banker, Kauffman and Morey, 1990]

3. the level of maturity of the organisation [Doll and Torkzadeh, 1987]

4. the methodology used in developing the IS plan [Lederer and Sethi, 1988; Bergeron, Buteau and Raymond, 1991]

5. the framework used for setting IT investment priorities [Burch, 1990]

6. the measurement of effectiveness used for the IS department [Clark, 1992]

7. preparation of an implementation plan is critical to meeting SISP objectives [Lederer \& Sethi, 1996]

Although these individual success factors have enjoyed much discussion, there have been few empirical attempts to relate the actual success of a SISP project to the detailed activities, techniques and processes which contributed to the that project. However, this literature has been be particularly important in this study by providing a set of metrics for measuring the successful application of SISP.

\subsection{Research Objectives}

The published literature confirms that strategic information systems planning is growing in importance for senior IS executives, and therefore remains high on the research agenda. The work of Earl [1993] has been particularly influential, as it introduces the concept of the SISP approach, which may be a more productive way of viewing the planning process. However, as Earl [1993; p17] himself noted: '.....additional studies are required to further validate and then perhaps develop these findings', and 'some of the parameters suggested here to distinguish the approaches could be taken as variables and investigated on larger 
samples to verify the classification.' The primary objective of this research was, therefore, to conduct an empirical study that sought to verify Earl's [1993] classification of SISP approaches. More specifically, it was possible to propose the following three important research objectives:

- To identify and validate a number of distinct and stable approaches to strategic information systems planning.

- To critically evaluate these approaches with respect to Earl's [1993] five approaches, and in so doing validate Earl's [1993] taxonomy.

- To explore the relationship between the derived SISP approaches and the resultant level of perceived success.

It was envisaged that by addressing these issues, it would not only be possible to validate the work of Earl [1993], but also to offer practical advice to IT practitioners with regard to the successful application of SISP. The remainder of this paper describes the piece of work that was conducted to explore these research objectives.

\section{Research Method}

The successful investigation of the research objectives is dependent upon the analysis of a large number of responses, and consequently survey research is the most suitable form of data collection. This section describes how a questionnaire was designed, validated and executed before reviewing the strategy used to analyse and interpret the responses.

\subsection{Questionnaire Design}

In order to address the three research issues highlighted in section 2.4 it was necessary to develop a series of measures that would adequately describe an organisation's planning practices and the level of success associated with the application of SISP. To maximise the reliability and validity of the research instrument, and to strongly embed the research within the existing literature, the questions used were, where possible, adapted from published research. Whilst the research of many authors (e.g. Byrd et al [1995]; Sabherwal \& King [1995] and Lederer \& Sethi [1996]) was instrumental in this process, it is the work of Earl [1993] and Segars [1994] which most strongly influenced the development of the research instrument. More specifically, Earl's [1993] study was most influential in focusing the questionnaire and selecting the research variables, whilst Segars' [1994] work played a particularly important role in the operationalisation of the variables. Following the examples of Earl [1993]; Segars [1994]; Byrd et al [1995] and Sabherwal \& King [1995], the SISP approach was conceptualised as a multi-faceted construct. However, in this study, ten 
distinct planning variables (P1-P10), as identified and defined in table 1, were employed to cover a broader range of SISP characteristics. Similarly, SISP success is best measured using 'multiple, interrelated success measures' [Segars \& Grover, 1998b]. The seven success variables (S1-S7), used in this study, are also presented, together with the most relevant sources, in table 1 . Both the planning practice and the SISP success variables were operationalised using five-point, semantic differential scales.

\section{Table 1 about here}

It can be seen from an inspection of the variables presented in table 1, that two of the variables; alignment and implementation feature explicitly in both the planning practice and success variables. Furthermore, the planning variable competitive focus is also implicitly matched with the success variable, contribution. This was a deliberate strategy to explore the extent to which our three defining characteristics of SISP, namely alignment, competitive focus and implementation, were explicitly focussed upon during an organisation's planning practices and realised as a result of a SISP exercise.

\subsection{Questionnaire Validation}

Having designed a draft questionnaire, it was further refined through a rigorous process of pre-testing and piloting. The pre-testing focused on issues of instrument clarity, question wording and validity. All participants in the pre-testing were asked to give their general impressions of the questionnaire, to comment on the adequacy of individual questions, and help to identify problems that might otherwise be overlooked. Ultimately, the questionnaire was pre-tested by a selection of twenty IT professionals, academics, and IS researchers, which led to a number of important enhancements being incorporated into the final version of the questionnaire. After the pre-testing a pilot study exercise was also undertaken to gain insights into likely respondent behaviour and response rates. The pilot study was targeted at $10 \%$ of the organisations in the sampling frame, and these yielded 20 usable responses. The pilot study provided valuable insights into the likely response rate and analytical implications for the full survey, but did not highlight any problems. Consequently, the questionnaire design was not altered after the pilot study.

\subsection{Survey Targeting and Execution}

The primary objectives of the targeting exercise were to determine which individuals and companies to target. Venkatraman [1989] suggests that the individual best placed to provide information on group or organisational attitudes and behaviour within information systems research projects, designated the 'key informant', is typically the Chief Information Officer (CIO). The equivalent of the $\mathrm{ClO}$ in British companies tends to be the IT Director. It is acknowledged that the research consequently reviews SISP as perceived by the IT Director, and that another functional head might have different perceptions. However, consistency is achieved and it is unlikely that any other single title could be targeted where the respondents 
would all share the same relationship with the information systems of the business. The choice of companies to target was influenced by Earl [1993] who had selected large organisations and consequently, a sampling frame of IT Directors from large private sector organisations was considered to be the best suited to the objectives of the research. The sampling frame was deliberately restricted to organisations operating in the private sector, as some of the planning concepts, such as competitive advantage are more readily applicable to commercial companies. The sample was ultimately drawn from the Financial Analysis Made Easy (FAME) database, which contains the trading addresses of all the UK's major organisations. Unfortunately, FAME's mailing list facility does not contain the names of IT Directors, and consequently the survey had to be targeted anonymously.

\subsection{An Overview of the Sample}

From the 2000 questionnaires distributed, 292 usable responses were collected; an overall response rate of $15 \%$. Given this good response rate and the high number of usable surveys, no follow-up mailing was deemed necessary. The introductory section of the questionnaire sought to capture basic demographic information about the responding organisations. An analysis of this data found that the distribution of the respondents over the economy appeared reasonably representative, in terms of organisational size and industrial sector. Table 2 gives a breakdown of industry sectors and company sizes represented in the responses. Furthermore, a comparison of 'early' and 'late' responses [Armstrong \& Overton, 1982] indicated that no detectable response bias exists in the sample and, therefore, that the results are generalisable within the boundary of the sample frame. Finally, of the 292 usable responses, 267 (91\%) indicated that they undertook some form of IS planning, and were therefore relevant to the issues explored in this paper.

\section{Table 2 about here}

\subsection{Data Analysis Strategy}

The primary objective of this piece of research was to identify distinctively different classes of approach to the application of SISP. Cluster analysis was selected to facilitate this aim, as it has been specifically designed to produce clusters or groups of highly similar entities. This method is especially useful when one is examining unexplored phenomena because both the nature and the number of categories can be determined by the populations [Hair et. al, 1995]. The resulting clusters of objects should then exhibit high internal (within-cluster) homogeneity and high external (between-cluster) heterogeneity, and result in clusters that are exhaustive, mutually exclusive and stable [Fiedler, Grover and Teng, 1996]. This study adopts a four-stage model-building approach for the cluster analysis, adapted from the one proposed by Hair et. al [1995]. A description of this process and its results are presented in section 4.1 of this paper.

\section{Research Results}


This section presents a discussion of the research results relating to the three specific research objectives proposed earlier.

\subsection{The Identification of Distinct SISP Approaches}

This section reviews the application of the clustering process [Hair et al, 1995] and in so doing demonstrates how a number of distinct SISP approaches were identified and validated. Given that all the clustering variables are metric, Ward's method (using squared Euclidean distances) was chosen for clustering, and it has the advantage of speeding up the computation considerably [Hair et. al, 1995]. Having embarked upon the clustering process the next major issue to address was the appropriate number of clusters to focus upon. As Earl [1993] had identified five distinct SISP approaches, it would have been helpful if a five cluster solution had naturally emerged from the data-set. However, a review of Ward's clustering coefficient [Norusis, 1993; Hair et. al, 1995] suggested that a four cluster solution was the most appropriate and consequently, it was this solution that was thoroughly evaluated to interpret and validate the clusters.

Whilst the cluster coefficient analysis suggests that the choice of four clusters is the most appropriate, from a statistical viewpoint, this result can only be supported if the four clusters can be meaningfully interpreted. As Rich [1992, p 777] notes a classification system is only meaningful if it: "mirrors the real world, describing organisational reality in a way that is recognisable to and consistent with the vision of practitioners and researchers alike as a viable reproduction of the diverse world in which we live and study". Table 3 exhibits the information that is necessary for the interpretation of the four clusters solution. For each cluster, the mean value (centroid) for each of the ten planning variables is provided. Furthermore, the analysis of variance reveals that the cluster means, for all ten variables, are significantly different at the 0.01 level, and therefore the four clusters represent distinct groups of respondees. However, the real 'acid test' for the appropriateness of the four cluster solution is whether it could be meaningfully interpreted, in the context of planning practice and the relevant literature, a process which is described in section 4.2 of this paper.

\section{Table 3 about here:}

Before interpreting the four cluster solution, it was important to validate these clusters to ensure that they were stable, distinct and meaningful. Firstly, the successful application of the validation methods suggested by Green, Tull and Albaum [1988, p. 588] provided strong evidence that the clusters were stable. The distinctiveness of the four clusters was partially confirmed by the results of the ANOVA presented in table 3 , but this was also supported by the results of a 'Bonferroni' test [Norusis, 1993] that confirmed the independence of the clusters. Finally, the meaningfulness of the clusters is demonstrated through the discussion of the research results presented in the following two sections. As a result of the clustering procedure described above, four clusters that were exhaustive, mutually exclusive, stable and consistent had been identified. 
The definition of SISP, presented in section 2, emphasises implementation, alignment with corporate strategy and ability to create competitive advantage. With this in mind, the defining characteristics of each of the four derived clusters are briefly described below:

- Cluster 1: This is the largest of the four clusters, accounting for $36 \%$ of the cases. An inspection of the data in table 3 shows that cluster 1 achieves the highest scores for alignment and competitive focus and a relatively high score for implementation. These characteristics align well with our previous definition of SISP, and suggest that this is the purest form of SISP being practised. The highest frequency score also suggests a continuing process of review and adjustment to maintain competitive position. Furthermore, the approach scores relatively highly in those aspects of planning practice, such as formality, comprehensiveness and implementation focus, that provide the disciplined approach to planning that may be necessary to deliver strategic objectives.

- Cluster 2: The second cluster is also the second largest of the four, accounting for $29 \%$ of the cases. This is something of a paradoxical approach. A creative focus and a high frequency, coupled with relatively high scores for competitive focus and alignment, suggest the beginnings of a strategically oriented planning approach, yet the low score for ownership, suggests that the process is owned by the IS function. Furthermore, the low scores for formality, comprehensiveness and implementation focus suggest that the process of planning might not be sufficiently structured to ultimately deliver its strategic goals. Overall, the feeling conveyed is of a learning organisation, moving towards true SISP, but not yet able to integrate business people into the planning process.

- Cluster 3: This Cluster accounted for $26 \%$ of the cases. In many ways the profile of a cluster 3 organisation is the antithesis of the characteristics of the cluster 1 approach. For example it can be seen that this planning approach does not explicitly seek to achieve strategic alignment, nor the attainment of competitive advantage. This suggests an information systems planning approach which lacks the high degree of strategic focus emphasised in our definition of SISP. Furthermore it can be seen that the approach is conducted infrequently and does not encourage high levels of user participation. Once more, this perhaps suggests a form of information systems planning that is relatively immature.

- Cluster 4: This is the smallest of the four clusters, accounting for just $9 \%$ of the total cases. This is a particularly interesting cluster, as it scores highly in terms of formality, comprehensiveness, control and implementation focus, yet scores relatively lowly in terms of alignment and competitive focus. This suggests a planning approach that is methodical, well structured and is directed towards the attainment of deliverables, yet one that lacks strategic impact. Such planning could well be practised in 
organisations that are still concentrating on the adoption of a systematic and wellstructured approach, rather than the realisation of a strategic contribution.

The four derived SISP approaches described briefly above differ greatly, especially with regard to their degree of strategic orientation and structure. These differences can be seen clearly in Figure 1, which uses a matrix to provide an overview of the predominant, and contrasting, characteristics of the four approaches. Whilst the discussion of the approaches has sought to summarise some of the most interesting characteristics of each of the four clusters, their distinctiveness becomes clearer when interpreted with respect to Earl's [1993] five approaches.

\section{Figure 1 about here}

\subsection{The Interpretation of the SISP Approaches}

In order to interpret the four derived clusters with respect to Earl's [1993] qualitative study it was necessary to develop a descriptive profile of each of his five approaches in terms of the ten planning variables. For most variables this was relatively simple as Earl [1993] had presented clear tabular or textual descriptions of the variable for each of the five approaches. For the remaining variables it was necessary to closely scrutinise the text of Earl's [1993] paper to find evidence, in order to help assign an appropriate descriptive value for each approach. For example, the degree of comprehensiveness with respect to the 'administrative' approach is not explicitly indicated. However, it is noted that the approach is not supported by a planning method, and it relies on individual business units or departments submitting proposals. It can be inferred from these clues that there is probably little attempt to be exhaustive in making and integrating decisions. Consequently, the 'administrative' approach's value for comprehensiveness was judged to be low. The full results of the interpretation process are presented in table 4.

\section{Table 4 around here}

What follows is an interpretation of the four clusters in relation to Earl's five approaches. In order to interpret the numerical results presented in table 3 , it was necessary to categorise each value using the same terms as Earl; most typically high, medium or low. Consequently, the standard normal curve was used in conjunction with the mean and standard deviation for each variable to specify the two boundaries between high, medium and low. The results of this process, which are presented in table 5 , could then be compared with the descriptive profiles of Earl's [1993] five approaches, as shown in table 4, to identify any similarities.

\section{Table 5 around here}

Cluster 1: A comparison of the profile of this cluster against Earl's [1993] five approaches suggests that it bears a resemblance to Earl's 'organisational' approach. As shown in table 6, six of the ten planning variables align very closely, whilst three of the remaining four, namely comprehensiveness, flow and ownership, are not absolutely opposed. Interestingly, in Earl's 
[1993] study it was the 'organisational' approach that was also the most commonly used, accounting for $29 \%$ of the companies studied.

\section{Table 6 around here}

It is also instructive to review some of the key phrases Earl [1993] uses to describe the 'organisational' approach to evaluate how closely they tie in with the characteristics of cluster 1. For example, Earl [1993] suggests that the 'underlying assumption' of the 'organisational' approach is that 'SISP is a continuous decision-making activity shared by the business and IS' and that is based upon 'management understanding and involvement'. These phrases suggest an approach that would be characterised by high scores for frequency, participation and alignment. Consequently, there is clear evidence that cluster 1 and the 'organisational' approach are strongly related. Indeed, the relationship is sufficiently strong to also name cluster 1 the 'organisational' approach. However, it must be emphasised that use of a common name does not imply that the two approaches are identical; it is simply an indication of the strong similarities that have been identified.

The rational adaptation approach [Segars et al., 1998a], embodies the principle of rationality through a high level of comprehensiveness, by formalisation and through a top-down planning flow, emphasising the importance of a structured approach driven by management. The principle of adaptation relates to a capacity to learn, achieved through wide participation and through frequent, perhaps continuous revising of the plan. In these respects, Rational adaptation and Earl's [1993] Organisational approach appear very similar. However, an apparent difference lies in the focus planning variable: the organisational approach admits a creative focus, in contrast to the control focus of rational adaptation.

Cluster 2: An inspection of characteristics of cluster 2, as presented in table 7, suggests that it demonstrates a high degree of correspondence with Earl's [1993] 'business-led' approach, with seven of the ten planning variables aligning closely. Furthermore, the remaining three variables: frequency, flow, and alignment are not absolutely opposed.

\section{Table 7 around here}

Alignment deserves particular comment here. The 'underlying assumption' of Earl's [1993] 'business-led' approach is that 'business plans and needs should drive IS plans'. However, Earl [1993] notes that in reality business plans 'are neither clear nor detailed enough to specify IS needs', and it may be that difficulties arise in seeking a high degree of strategic alignment throughout the planning process. Consequently, an alignment rating for cluster 2 of medium, rather than high, in this critical dimension of SISP, doesn't necessarily mean the two approaches are not related. Indeed, in other important aspects the two approaches are clearly very similar. For example, Earl [1993] notes that in the 'business-led' approach: 'users and line managers are likely to be involved very little'; it is 'the responsibility of the IS Director or IS strategic planner', and 'procedures are developed on a trial and error basis'. These 
comments tie in very closely with an approach that attracts very low scores for participation and formality and is owned by the 'IS group'. In summary, it can be seen that although cluster 2 and the 'business-led' [Earl,1993] approaches are clearly not identical, the similarities between the two approaches are sufficiently strong to warrant naming cluster 2 the 'business-led' approach.

Cluster 3: An inspection of table 8 suggests that cluster 3 exhibits a marked resemblance to Earl's [1993]'administrative' approach. Six of the ten planning variables align closely. Of the other four variables, two planning characteristics, namely frequency and participation, are not absolutely opposed, whilst the remaining two, implementation focus and the degree of formalisation, are clearly different. Inspecting the text of Earl's [1993] paper once more provides some further interesting insights into the relationship between cluster 3 and the 'administrative' approach. Earl suggests that the approach is 'bottom-up rather than topdown' and 'strategic thinking was absent'. These observations tie in very well with cluster 3's scores for flow, alignment and competitive focus. Furthermore, the 'underpinning assumption' is that 'SISP should follow and conform with the firm's management planning and control procedures', which may explain the strong 'control' focus in cluster 3.

\section{Table 8 around here}

It can be argued that there is a fair correspondence between cluster 3 and the 'administrative' approach, sufficient to believe that the two may be strongly related and can share a common name. However, it must be stressed that the two approaches are not identical, as Earl's [1993] 'administrative' method is the more structured of the two sets of planning practices, with its higher levels of 'procedural' formality and its more explicit focus on implementation

Cluster 4: Given the results above, it would be convenient if cluster 4 aligned closely with one of the two remaining approaches from Earl's [1993] work, namely 'technological' and 'method driven', which are in any case quite strongly related, as shown by the last two columns of table 4. Unfortunately, the situation is less simple. As demonstrated in table 9, cluster 4 parallels the method driven and technological approaches in a number of key variables. Flow is the only variable that strongly differentiates Earl's [1993] two approaches, and in this respect, cluster 4 aligns with the 'technological' approach. However, in comprehensiveness, implementation focus and participation, cluster 4 is diametrically opposed to both of Earl's [1993] approaches. Thus, cluster 4 lacks sufficient congruence with either the 'method driven' or 'technological' approaches, to claim that it is related strongly to either of these. However, since it ranks highest in terms of formality and comprehensiveness it suggests an approach that is explicit, expansive and rigorous, and consequently, it has been named the 'systematic' approach. As this is somewhat different to Earl's [1993] existing approaches, the 'real world' nature of this cluster warrants further research. 


\section{Table 9 around here}

The results presented above do not prove that there are only four distinct approaches to SISP, rather than the five identified by Earl [1993]. It is possible that a more sophisticated questionnaire, attracting a larger number of responses, and analysed using different techniques, might be more discriminating. However, taking both pieces of research together, they do present a plausible and coherent case that there are only a small number of underlying SISP approaches, which can be distinguished in terms of a number of key planning practices.

\subsection{The Relative Success of the four SISP Approaches}

The previous sections presented and discussed the methods by which four distinct SISP approaches were identified and interpreted. The purpose of this section is to investigate the degree of success associated with each of these approaches. This study explores the degree of success by using 5-point Likert scales ( $1=$ not successful, $5=$ highly successful) to explore respondents' perceptions of the success of their SISP activity in seven different dimensions, namely: alignment, analysis, capability, contribution, co-operation, implementation and satisfaction. These values were then used to explore the relationship between the application of a specific SISP approach and the resultant level of success. The results of an analysis of variance (ANOVA) between the SISP success variables and the four SISP approaches, presented in table 10, shows that the approaches are significantly different on all success variable except for the 'extent of analysis' variable. In addition to providing insights into the relative success of the different approaches, these results are also of interest, because they provide further evidence that the four clusters are valid. As Punj and Stewart [1984] explain:

'the ultimate test of a set of clusters is its usefulness. Thus, the analysis should provide a demonstration that clusters are related to variables other than those used to generate the solution.'

Consequently, the significant results of the ANOVA can be viewed as an 'external validation' [Saunders, 1999], which provides further confirmation that the four clusters are meaningful, rather than random collections of planning characteristics.

\section{Table 10 around here}

Table 10 clearly indicates that the 'organisational' approach has the highest group means for all the seven measures of success, and is consequently perceived as being more successful than the three other approaches. The next most successful approaches are the 'businessled' and 'systematic' approaches, whose mean ratings are very similar. Finally, most of the group means for the 'administrative' approach are lower than for the other three approaches. 
Interestingly, it was expected that the 'systematic' approach would score highest for extent of analysis and extent of implementation, as this approach is highly formal and has a strong focus on implementation. Thus, there is, in this case, a perceived difference between what the approach attempts and what it achieves.

These findings are very important because they confirm, using a highly rigorous statistical approach, the primary conclusions of Earl's [1993] qualitative work; namely that the 'organisational' approach is the most effective, and the 'administrative' is the least effective. Furthermore, these findings also add weight to the work of Segars et al [1998a] who have demonstrated that their 'rational adaptation' approach, which is very similar to the 'organisational' approach, is the most effective way of organising SISP activity. Consequently, three individual but related pieces of work, using very different research instruments, different analytical approaches and different target audiences, have all identified a single distinct SISP approach which shares many common characteristics and is shown to be more effective than alternative approaches.

Having explored the relative success of the four approaches, it is important to relate these results to the published literature, to understand why the 'organisational' is the most successful of the four approaches, and the 'administrative' the least successful. Starting with the 'organisational' approach, it is not surprising that this approach delivers effective planning outcomes, because it explicitly embodies many of the key prescriptions and success factors identified in the literature. For example, Lederer \& Sethi [1996] highlight the importance of both a strong implementation focus and high levels of creativity, whilst King \& Teo [1997] note the importance of user participation in the planning process and the need for a strong competitive focus. Galliers [1991] suggests that the two most important SISP success factors are senior management commitment and senior management involvement, echoing the strongly business-led, top-down orientation of the 'organisational' approach. Furthermore, the desirability of a high degree of alignment has been highlighted by Reich \& Benbasat [1999], while the need for regular reviews and revisions has been identified by Das et al [1991]. The only characteristics of the 'organisational' approach not previously cited as SISP success factors are the high degree of comprehensiveness and formality. This is an important finding, as it suggests that high formality and comprehensiveness should be added to the other success factors to provide a coherent framework for the practice of SISP. By contrast to the 'organisational approach', it is likely that the 'administrative' approach is less likely to deliver successful planning outcomes because it does not directly incorporate key elements of best practice.

Finally, it is interesting to note that the 'organisational' approach achieves the highest planning practice scores for the 'alignment' and 'competitive focus' variables, and a high score for 'implementation focus' (see table 3). The 'organisational' approach, therefore, 
aligns well with the stated definition of SISP, which explicitly emphasises the importance of 'identifying a portfolio of computer-based applications to be implemented, which is both highly aligned with corporate strategy and has the ability to create an advantage over competitors. Consequently, one interpretation of these results may be that the 'organisational' approach is the most effective because it is the 'purest' form of strategic information systems planning.

\section{Conclusions}

This empirical study has developed a taxonomy for SISP approaches based on ten key planning dimensions. By applying a multi-step cluster analysis to the responses from 267 companies, four clusters were derived which have been shown to be exhaustive, mutually exclusive, stable and consistent. Having compared these four clusters with the five approaches identified in an earlier work by Earl [1993], it became clear that three of the derived clusters show a high level of congruence with Earl's [1993] 'organisational', 'business-led' and 'administrative' approaches. However, whilst the fourth cluster appears to be associated with Earl's [1993] 'method-driven' and 'technological' approaches, it is sufficiently distinct to be given a unique label, namely the 'systematic' approach. The generally high levels of consistency between the two studies are significant because they add credibility to both the sets of findings, and consequently their implications are likely to be more generalisable. Furthermore, these results are important because they provide strong empirical evidence that SISP is a multi-faceted approach, rather than being simply a unidimensional method or a technique.

In a highly competitive business world where information technology plays an increasingly important strategic role, the need for effective strategic information systems planning practices has become critical. This study has a number of implications for the practice and application of strategic information systems planning. For example, organisations should be in a better position to apply SISP if they have an explicit understanding of the SISP approach used, in terms of the planning practices adopted, and the alternatives available. Moreover, the strong relationship between SISP approach and the resultant level of SISP success provides some practical insights into how strategic planning practices might be modified to improve their effectiveness. However, given the unique circumstances and requirements of each individual organisation, it is unlikely that there is a single prescription that is universally appropriate. Consequently, whilst it might be appropriate in some instances for an enterprise to adopt the 'organisational' approach in its entirety, other organisations might be better served by simply modifying certain aspects of their planning practices; for example, by encouraging higher levels of participation or creativity. 
Whilst the work reported in this paper provides a significant contribution to the understanding of SISP approaches and SISP success, there is still much further work in this area to be addressed. It must be recognised that the results of this study are based upon statistical analysis and they are therefore measuring 'association' rather than 'causality'. Whilst there is strong likelihood that success is the dependent variable and the SISP approach an important causal factor in this study, there is still a requirement for further research to investigate this relationship more thoroughly. For example, detailed, longitudinal case studies would allow the issue of causality to be far more thoroughly evaluated. A further important issue that this study has not addressed is conditionality. It may for example, be that whilst the 'organisational' approach is generally the most effective approach, there may be circumstances in which other approaches are more appropriate. Finally, this research targeted IT Directors alone, and thus reports their particular perspective. A more detailed study of fewer organisations, but involving cross-functional data gathering, would give an understanding of the variation in views held across functions. There are, therefore, many further lines of enquiry to be addressed in this increasingly important research domain.

\section{Acknowledgements}

The authors would like to thank all of those IT Directors who gave up their time to participate in this project, especially those who pre-tested the questionnaire. We are also very grateful for the many helpful suggestions made with respect to initial drafts of this paper by the three anonymous referees. 


\section{References}

Armstrong, J. S. \& Overton, T. A. (1982) 'Estimating non-response bias in mail surveys', in Marketing Research: Applications and Problems, eds. Jain, A., Pinson, C. \& Ratchford, B., John Wiley \& Sons, Chichester.

Banker, R., Kauffman, R. \& Morey, R. (1990) 'Measuring gains in operational efficiency from IT: A study of the Positran deployment at Hardee's Inc' Journal of Management Information Systems Fall, pp 29-54.

Bergeon, F., Buteau, C., \& Raymond, L. (1991) 'Identification of Strategic Information Systems Opportunities: Applying and Comparing two Methodologies', MIS Quarterly 15 (1), pp 89-103.

Burch, J. (1990) 'Planning and Building Strategic Information Systems', Journal of Systems Management, 14 (7), pp 21-27.

Byrd, T. A., Sambamurthy, V., \& Zmud, R. W. (1995). 'n examination of IT planning in a large, diversified public organisation' Decision Sciences, 26(4), 49-73.

Clark, T. D. (1992) 'Corporate Systems Management: An Overview and Research Perspective' Communications of the ACM 35 (2), pp 61-75

Doll, W. J. and Torkzadeh, G. (1987) 'The relationship of MIS steering committees to size or firm formalisation of MIS planning' Communications of the ACM 30 (11), 972-997.

Earl, M. J. (1993) 'Experiences in Strategic Information Systems Planning', MIS Quarterly March, pp 1-24.

Fiedler, K., Grover, V. and Teng, J. (1996) 'An Empirically Derived Taxonomy of IT Structure and its relationship to organisational structure' Journal of Information Management Systems 13 (1), pp 9-34.

Galliers, R. D. (1991) 'Strategic information systems planning: myths, reality and guidelines for successful implementation', European Journal of Information Systems, 1 (1), pp 55-64.

Galliers R. D. (1993) 'Research Issues in Information Systems' Journal of Information Technology 8, pp 92-98.

Galliers R. D., Merali, Y. \& Spearing, L. (1994) 'Coping with information technology? How British Managers perceive the key issues in the mid 1990's', Journal of Information Technology, 9 (4), 223-238.

Green, P., Tull, D. and Albaum, G. (1988) 'Research for Marketing and Cluster Analysis' Journal of Marketing Research, 6, pp 359-364.

Hair, J. et. al, (1995) Multivariate Data Analysis with Readings, Prentice Hall, New Jersey.

Henderson, J. (1990) 'Plugging into Strategic Partnerships: The Critical IS Connection', Sloan Management Review, 31 (3), pp 7-18.

Henderson , J. \& Venkatraman, N. (1993) 'Strategic Alignment: Leveraging information technology for transforming organisations' IBM Systems Journal 32 (1), pp 4-15.

King, W. R. (1978) 'Strategic Planning for Management Information Systems', MIS Quarterly 2 (1), pp 27-37.

King, W. R. \& Teo, T. (1997) 'Integration between Business Planning and Information Systems Planning: Validating a Stage Hypothesis', Decision Sciences, 28 (2), pp 279-308.

Lederer, A. L. and Mendelow, A. L. (1989) 'Co-ordination of Information Systems Plans with Business Plans' Journal of Management Information Systems 6 (2), pp 5-19

Lederer, A. and Sethi, V. (1988) 'The Implementation of Strategic Information Systems Planning Methodologies' MIS Quarterly September, pp 445-461

Lederer, A. L. and Sethi, V. (1991) 'Critical Dimensions of Strategic Information Systems Planning' Decision Sciences 22 (1), pp 104-119. 
Lederer, A. L. and Sethi, V. (1992) Meeting the challenges of information systems planning. Long Range Planning, 25(2), 69-80.

Lederer, A. L. and Sethi, V. (1996) 'Key Prescriptions for Strategic Information Systems Planning' Journal of Management Information Systems 13 (1), pp 35-62.

McLean, E. R. and Soden, J. V. (1977) Strategic Planning for MIS, John Wiley \& Sons, Inc., New York.

Nierderman et al, (1991) 'Information Systems Management Issues for the 1990s' MIS Quarterly 15 (4), pp 475-500.

Norusis, M. (1993) SPSS for Windows for Professional Statisticians, SPSS Inc., Michigan.

Punj, G. \& Stewart, D. (1984) Cluster Analysis in Marketing Research: Review and Suggestions for Application', Journal of Marketing Research, 20 (2), pp 134-148.

Rich, P. (1992) 'The organisational taxonomy - definition and design' Academy of Management Review 17 (4), pp 758-781.

Reich, B. \& Benbasat, I. (1999), 'Measuring the Information Systems - Business Strategy Relationship' in Strategic Information Management, Galliers, R. Leidner, D. \& Baker, B. (eds), Butterworth-Heinemann, Oxford, pp329-366.

Sabherwal, R. \& King, W. (1995) 'An empirical taxonomy of the decision-making processes concerning strategic applications of information systems' Journal of Management Information Systems 11 (1), pp 177-214.

Saunders, J. (1999) 'Cluster Analysis' in Quantitative Methods in Marketing, Hooley, G. \& Hussey, M. (eds), Thompson Business Press, London, pp 41 - 59.

Segars, A. (1994) SISP: The co-alignment of planning systems design, unpublished dissertation, University of North Carolina.

Segars , A., Grover, V. \& Teng, T. (1998a) 'Strategic Information Systems Planning: Planning System Dimensions, Internal Coalignment, and Implications for Planning Effectiveness' Decision Sciences 29 (2), pp 303-341.

Segars, A. \& Grover, V. (1998b) 'Strategic Information Systems Planning Success: An Investigation of the Construct and its Measurement', Management Information Systems Quarterly, June, pp 139-163.

Venkatraman, N. (1989) 'Research on MIS Planning: Some guidelines from Strategic Planning Research' Journal of Management Information Systems 2 (3), pp 65-77.

Ward, J. (1987) Integrating information systems into business strategies' Long Range Planning, 2 (3), pp 19-29. 
Table 1: Definitions for the Planning \& Success Variables

\begin{tabular}{|c|c|c|}
\hline Variable & Definition & Primary Sources \\
\hline $\begin{array}{l}\text { P1 Comprehensive- } \\
\text { ness }\end{array}$ & $\begin{array}{l}\text { The extent to which an organisation attempts to be exhaustive in } \\
\text { making and integrating decisions }\end{array}$ & $\begin{array}{l}\text { Byrd et al (1995); } \\
\text { Segars (1994)* }\end{array}$ \\
\hline P2 Formalisation: & $\begin{array}{l}\text { The existence of structures, techniques and written procedures to } \\
\text { support the planning process. }\end{array}$ & $\begin{array}{l}\text { Byrd et al (1995); } \\
\text { Segars (1994)* }\end{array}$ \\
\hline P3 Focus: & $\begin{array}{l}\text { The balance between the application of financial control in } \\
\text { considering applications, versus the welcoming of more creative } \\
\text { contributions appraised through non-financial criteria. }\end{array}$ & $\begin{array}{l}\text { Lederer \&Sethi } \\
(1996) ; \text { Segars } \\
(1994)^{*}\end{array}$ \\
\hline P4 Flow: & $\begin{array}{l}\text { The locus of authority or devolution of responsibilities for } \\
\text { strategic planning (bottom up, top down or interactive) }\end{array}$ & $\begin{array}{l}\text { Earl (1993) Segars; } \\
(1994)^{*}\end{array}$ \\
\hline P5 Participation: & $\begin{array}{l}\text { The breadth of involvement in the strategic planning process } \\
\text { (narrow v wide) }\end{array}$ & $\begin{array}{l}\text { Earl (1993); Segars } \\
(1994)^{*}\end{array}$ \\
\hline P6 Frequency: & $\begin{array}{l}\text { The frequency of planning activities or cycles (occasional } \mathrm{v} \\
\text { continuous) }\end{array}$ & $\begin{array}{l}\text { Earl (1993); Segars } \\
(1994)^{*}\end{array}$ \\
\hline P7 Alignment & $\begin{array}{l}\text { The degree to which alignment between corporate and IS } \\
\text { strategies is explicitly sought. }\end{array}$ & $\begin{array}{l}\text { Earl (1993); Lederer } \\
\text { \& Sethi (1996) }\end{array}$ \\
\hline P8 Ownership & $\begin{array}{l}\text { The locus of ownership for the planning process (business / IS } \\
\text { group / mixed) }\end{array}$ & $\begin{array}{l}\text { Earl (1993); } \\
\text { Henderson (1990) }\end{array}$ \\
\hline P9 Implementation & $\begin{array}{l}\text { Focus during the planning process on the implications for } \\
\text { implementation }\end{array}$ & $\begin{array}{l}\text { Earl (1993); Lederer } \\
\text { \& Sethi (1996) }\end{array}$ \\
\hline $\begin{array}{l}\text { P10 Competitive } \\
\text { focus }\end{array}$ & $\begin{array}{l}\text { The range of benefits sought (primarily efficiency v wider } \\
\text { benefits, including competitive advantage) }\end{array}$ & $\begin{array}{l}\text { Earl (1993); Lederer } \\
\text { \& Sethi (1996) }\end{array}$ \\
\hline S1 Satisfaction & $\begin{array}{l}\text { The extent to which participants feel that effort expended on the } \\
\text { SISP exercise has been time well spent }\end{array}$ & $\begin{array}{l}\text { Earl (1993); Segars } \\
(1994)^{*}\end{array}$ \\
\hline S2 Alignment & The degree of closeness between IS and corporate strategies. & $\begin{array}{l}\text { Earl (1993); Segars } \\
\text { (1994)* }^{*}\end{array}$ \\
\hline S3 Contribution & $\begin{array}{l}\text { The extent to which SISP contributes to the overall effectiveness } \\
\text { of the organisation. }\end{array}$ & $\begin{array}{l}\text { Segars }(1994)^{*} \\
\text { Lederer \& Sethi } \\
(1988)\end{array}$ \\
\hline S4 Implementation & $\begin{array}{l}\text { The extent to which strategic information system plans have, or } \\
\text { are thought likely to be, implemented. }\end{array}$ & $\begin{array}{l}\text { Earl (1993) ); } \\
\text { Lederer \& Sethi } \\
(1996)\end{array}$ \\
\hline S5 Analysis & $\begin{array}{l}\text { The ability to understand the internal operations of the } \\
\text { organisation in terms of its processes, procedures etc. }\end{array}$ & $\begin{array}{l}\text { Segars }(1994)^{*} \text {; } \\
\text { Lederer \& Sethi } \\
\text { (1988) }\end{array}$ \\
\hline S6 Capability & $\begin{array}{l}\text { An improvement, over time, in the capability of the planning } \\
\text { process to support effective IS planning }\end{array}$ & Segars $(1994)^{*}$ \\
\hline S7 Co-operation & $\begin{array}{l}\text { The achievement of general agreement concerning development } \\
\text { priorities, implementation schedules etc. }\end{array}$ & $\begin{array}{l}\text { Henderson (1990); } \\
\text { Segars (1994) }\end{array}$ \\
\hline
\end{tabular}

\footnotetext{
* It should be noted that whilst the original source for this material was Segar's (1994) PhD thesis, this work has
} also been reported more recently in Segars et al (1998a). 
Table 2: Industry sectors by Total Number of Employees

\begin{tabular}{|c|c|c|c|c|c|c|}
\hline \multicolumn{7}{|c|}{ Total number of employees } \\
\hline Industrial sector & $\begin{array}{l}\text { Less than } \\
1500\end{array}$ & $\begin{array}{l}1500- \\
2999\end{array}$ & $\begin{array}{l}3000- \\
4499\end{array}$ & $\begin{array}{l}4500- \\
5999\end{array}$ & $\begin{array}{l}\text { More than } \\
6000\end{array}$ & $\begin{array}{l}\text { Row } \\
\text { Total }\end{array}$ \\
\hline Manufacturing & 50 & 31 & 14 & 3 & 19 & 117 \\
\hline Services & 29 & 30 & 14 & 11 & 37 & 121 \\
\hline Other & 21 & 10 & 5 & 5 & 12 & 53 \\
\hline Column total & 100 & 71 & 33 & 19 & 68 & 291 \\
\hline
\end{tabular}


Table 3: Mean Ratings and Significance Levels for Planning Variables

\begin{tabular}{lcccccc}
\hline Planning Variables & Cl. 1 & Cl. 2 & Cl. 3 & Cl. 4 & F. Ratio & F. Prob. \\
\hline Comprehensiveness & 2.88 & 2.27 & 2.09 & 3.52 & 24.96 & .00 \\
Flow & 2.28 & 2.45 & 3.12 & 2.84 & 11.07 & .00 \\
Focus & 4.03 & 3.61 & 3.07 & 1.92 & 34.02 & .00 \\
Formalisation & 2.93 & 2.35 & 2.44 & 3.48 & 14.05 & .00 \\
Frequency & 3.62 & 3.58 & 2.07 & 3.32 & 44.82 & .00 \\
Implementation & 2.61 & 2.13 & 1.99 & 3.20 & 12.41 & .00 \\
Ownership & 3.88 & 2.20 & 2.50 & 3.04 & 53.87 & .00 \\
Participation & 3.20 & 1.96 & 1.69 & 2.96 & 42.03 & .00 \\
Alignment & 4.44 & 4.12 & 3.12 & 4.20 & 35.81 & .00 \\
Competitive focus & 4.44 & 3.97 & 3.06 & 3.04 & 35.67 & .00 \\
\hline
\end{tabular}


Table 4: The Descriptive Interpretation of Earl's (1993) Approaches

\begin{tabular}{|c|c|c|c|c|c|}
\hline $\begin{array}{l}\text { Planning } \\
\text { Variables }\end{array}$ & $\begin{array}{l}\text { Organisa- } \\
\text { tional }\end{array}$ & $\begin{array}{l}\text { Business } \\
\text { Led }\end{array}$ & $\begin{array}{l}\text { Administ- } \\
\text { rative }\end{array}$ & $\begin{array}{l}\text { Method } \\
\text { driven }\end{array}$ & $\begin{array}{l}\text { Techno- } \\
\text { logical }\end{array}$ \\
\hline $\begin{array}{l}\text { Comprehen- } \\
\text { siveness }\end{array}$ & Medium & Low & Low & Low & Low \\
\hline Flow & Interactive & Top down & Bottom up & Top down & Bottom up \\
\hline Focus & Creative & Creative & Control & Control & Control \\
\hline Formalisation & Low & $\begin{array}{l}\text { Low - } \\
\text { 'homespun' }\end{array}$ & High & Very high & High \\
\hline Frequency & $\begin{array}{l}\text { High } \\
\text { (continuous) }\end{array}$ & $\begin{array}{l}\text { Medium - } \\
\text { annual }\end{array}$ & Medium & $\begin{array}{l}\text { Depends on } \\
\text { method }\end{array}$ & Low \\
\hline Implementation & High & Medium & High & Low & Low \\
\hline Ownership & Partnership & IS & $\begin{array}{l}\text { IS Steering } \\
\text { Committee }\end{array}$ & $\begin{array}{l}\text { IS / } \\
\text { consultants }\end{array}$ & IS group \\
\hline Participation & High & Low & Medium & Low & Low \\
\hline Alignment & High & High & Low & $\begin{array}{l}\text { Depends on } \\
\text { method }\end{array}$ & Low \\
\hline $\begin{array}{l}\text { Competitive } \\
\text { focus }\end{array}$ & Highest & $\begin{array}{l}\text { Medium - } \\
\text { variable }\end{array}$ & Low & High & Low \\
\hline
\end{tabular}


Table 5: The Interpretation of Planning Variable Mean Ratings: Clusters 1 - 4

\begin{tabular}{lllll}
\hline Planning Variables & $\mathbf{1}$ & $\mathbf{2}$ & $\mathbf{3}$ & $\mathbf{4}$ \\
\hline Comprehensiveness & High & Low & Lowest & Highest \\
Flow & Top down & Interactive & Bottom up & Bottom up \\
Focus & High creativity & Creative & Control & High Control \\
Formalisation & High & Lowest & Low & Highest \\
Frequency & Highest & High & Lowest & Medium \\
Implementation & High & Medium & Lowest & Highest \\
Ownership & Business & IS & IS & Business / IS \\
Participation & Highest & Low & Lowest & High \\
Alignment & Highest & Medium & Lowest & Medium \\
Competitive focus & Highest & Medium & Low & Lowest \\
\hline
\end{tabular}


Table 6: Comparing Cluster 1 with the 'Organisational' Approach (Earl, 1993) and Segar's (1998) 'Rational Adaptation'.

\begin{tabular}{llll}
\hline Planning Variables & Cluster 1 & $\begin{array}{l}\text { Organisational } \\
\text { Approach }\end{array}$ & Rational Adaptaion \\
\hline Comprehensiveness & High & Medium & High \\
Flow & Top Down & Interactive & Top Down \\
Focus & Highly Creative & Creative & High \\
Formalisation & High & Low & High \\
Frequency & Highest & High (continuous) & High \\
Implementation & High & High & \\
Ownership & Business (highest) & Partnership & High \\
Participation & Highest & High & \\
Alignment & Highest & High & \\
Competitive focus & Highest & Highest & \\
\hline
\end{tabular}


Table 7: Comparing Cluster 2 with the 'Business-led' Approach (Earl, 1993)

\begin{tabular}{lll}
\hline Planning Variables & Cluster 2 & Business Led Approach \\
\hline Comprehensiveness & Low & Low \\
Flow & Interactive & Top Down \\
Focus & Creative & Creative \\
Formalisation & Lowest & Low - 'homespun' \\
Frequency & High & Medium - annual \\
Implementation & Medium & Medium \\
Ownership & IS & IS \\
Participation & Low & Low \\
Alignment & Medium & High \\
Competitive focus & Medium & Medium - variable \\
\hline
\end{tabular}


Table 8: Comparing Cluster 3 with the 'Administrative' Approach (Earl, 1993)

\begin{tabular}{lll}
\hline Planning Variables & Cluster 3 & $\begin{array}{l}\text { Administrative } \\
\text { Approach }\end{array}$ \\
\hline Comprehensiveness & Lowest & Low \\
Flow & Bottom-up & Bottom-up \\
Focus & Control & Control \\
Formalisation & Low & High \\
Frequency & Lowest & Medium \\
Implementation & Lowest & High \\
Ownership & IS & IS steering committee \\
Participation & Lowest & Medium \\
Alignment & Lowest & Low \\
Competitive focus & Low & Low \\
\hline
\end{tabular}


Table 9: Comparing Cluster 4 with the 'Method-driven' and 'Technological' Approaches (Earl, 1993)

\begin{tabular}{llll}
\hline Planning Variables & Cluster 4 & Technological & Method Driven \\
\hline Comprehensiveness & Highest & Low & Low \\
Flow & Bottom-up & Bottom up & Top-down \\
Focus & Highly controlled & Control & Control \\
Formalisation & Highest & High & Very high \\
Frequency & Medium & Low & Depends on Method \\
Implementation & Highest & Low & Low \\
Ownership & Business/IS & IS group & IS/Consultants \\
Participation & High & Low & Low \\
Alignment & Medium & Low & Depends on Method \\
Competitive focus & Lowest & Low & High \\
\hline
\end{tabular}


Table 10: One-way ANOVA between SISP Success and SISP Approaches

\begin{tabular}{|c|c|c|c|c|c|c|c|}
\hline \multirow[b]{2}{*}{ SISP SUCCESS } & \multicolumn{4}{|c|}{ SISP APPROACHES } & \multirow[b]{2}{*}{$\begin{array}{c}\mathrm{F} \\
\text { ratio }\end{array}$} & \multirow[b]{2}{*}{$\begin{array}{c}\mathrm{F} \\
\text { prob. }\end{array}$} & \multirow[b]{2}{*}{ Significance } \\
\hline & $\begin{array}{l}\text { Organis } \\
\text {-ational }\end{array}$ & $\begin{array}{l}\text { Busi- } \\
\text { ness }\end{array}$ & $\begin{array}{l}\text { Admini- } \\
\text { strative }\end{array}$ & $\begin{array}{c}\text { System- } \\
\text { atic }\end{array}$ & & & \\
\hline Extent of alignment & 4.1 & 3.7 & 3.2 & 3.6 & 16.84 & .0000 & Significant \\
\hline Extent of analysis & 3.8 & 3.5 & 3.6 & 3.5 & 1.77 & .1532 & Not significant \\
\hline Extent of capability & 3.5 & 3.3 & 3.2 & 3.3 & 2.51 & .0596 & *Significant \\
\hline Extent of contribution & 4.0 & 3.7 & 3.3 & 3.6 & 10.43 & .0000 & Significant \\
\hline Extent of cooperation & 3.8 & 3.5 & 3.2 & 3.4 & 5.75 & .0008 & Significant \\
\hline Extent of implementation & 3.7 & 3.6 & 3.3 & 3.6 & 3.81 & .0107 & Significant \\
\hline Extent of satisfaction & 3.8 & 3.4 & 3.1 & 3.7 & 10.73 & .0000 & Significant \\
\hline
\end{tabular}

* Significant at 10 percent level 


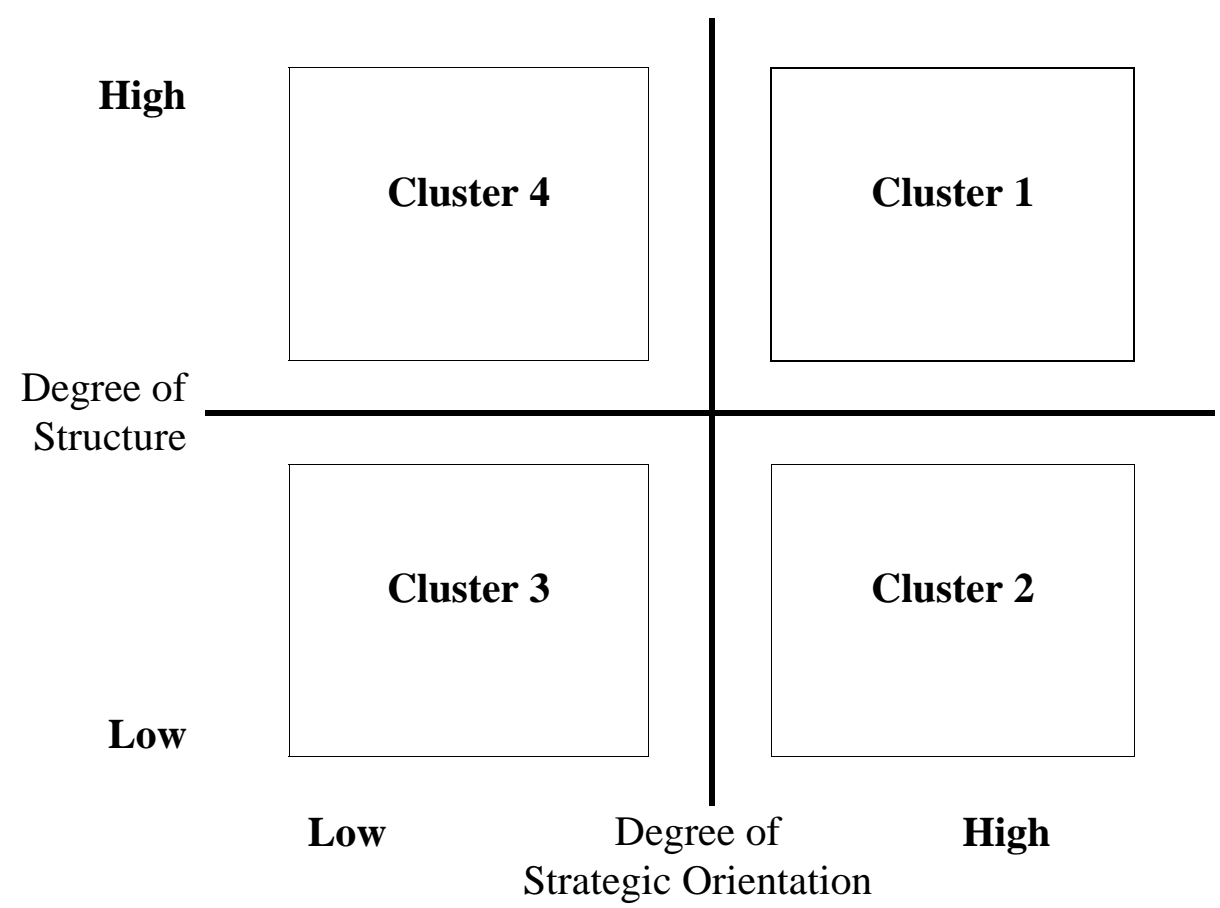

Figure 1: The contrasting characteristics of the four SISP approaches 